\title{
Vibration busters: An interdisciplinary approach to learning of dynamical systems
}

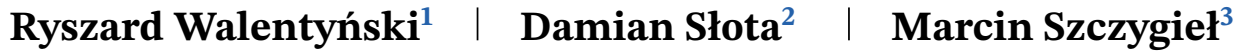

${ }^{1}$ Department of Mechanics and Bridges, Faculty of Civil Engineering, Silesian University of Technology, Gliwice, Poland

${ }^{2}$ Department of Mathematics Applications and Methods for Artificial Intelligence, Faculty of Applied Mathematics, Silesian University of Technology, Gliwice, Poland

${ }^{3}$ Department of Mechatronics, Faculty of Electrical Engineering, Silesian University of Technology, Gliwice, Poland

\section{Correspondence}

Ryszard Walentyński, Department of Mechanics and Bridges, Faculty of Civil Engineering, Silesian University of Technology, Akademicka 5, 44-100 Gliwice, Poland.

Email: ryszard.walentynski@polsl.pl

\section{Funding information}

European Funds of the Operational Program Knowledge Education Development, Grant/Award Number: POWR.03.05.00IP.08-00-PZ1/17
A group of six pre-graduated students of Civil Engineering, Mathematics and Mechatronics studied problems of dynamics of structures within a project called Vibration Busters implemented in a formula of Project Based Learning. They worked under supervision of professors from the above mentioned faculties. Students, according to their competencies, implemented a procedure of numerical analysis of the problem within Mathematica system, built a physical model of a frame and loaded it with vibrating electrical motors and measured behaviour of the structure. The aim of the project was to develop methods of passive and active controlling of vibrations of building structures. A technology of 3D printing was implemented to build a structure. Thanks to the project students had an opportunity to share their skills and knowledge and acquire several new hard and soft skills. It was also a unique experience for supervisors and a great opportunity to extend fields of interdisciplinary cooperation. The aim of the presentation is to share results and experience gained thanks to this extraordinary and successful educational project.

\section{KEYWORDS}

dynamical system, mechatronics, project based learning, vibrations

\section{1 | INTRODUCTION}

Project Based Learning [1-6] formula is an innovative way of student education which introduces soft skills connected to project management and team cooperation among not only students and supervisors from different faculties but also faculties themselves. The possibilities of using project based learning in teaching civil engineering, mechatronics and mathematics are described in the papers [7-13]. Vibration busters [14] is a generic name of the project implemented within a program [15] at the Silesian University of Technology. It was a second edition of the project "Individual Study Programs implemented in the form of Project Based Learning", This edition was directed to the pre-graduate students (Bachelor). Recruited students were awarded with Individual Study Programs (IPS) where half of European Credit Transfer Points (ECTS) are gained thanks to the IPS. Consequently some subjects of the regular courses were replaced, but required effects of learning had to be fulfiled. Thirty-one proposals of the projects were been submitted in that edition [16]. They were evaluated by experts and 12 of them were awarded. Our proposal got the highest score as it was the most interdisciplinary and satisfied also other requirements of PBL formula. The students to the project were recruited according to their achievements in studies and activity in other projects. All selected students studied on 6th semester of the bachelor level (pre-graduate). 


\section{1 | Supervisors and expert}

The work of the students was supervised by three professors: Ryszard Walentyński-the main supervisor from the Faculty of Civil Engineering, Damian Słota-the auxiliary supervisor from the Faculty of Applied Mathematics, and Marcin Szczygie-the auxiliary supervisor from the Faculty of Electrical Engineering. To sort out specific problems an expert prof. Wojciech Burlikowski was employed to give several lectures and tutorials for students.

\section{2 | Students}

The following students were recruited to the Vibration Busters project: Grzegorz Fulczyk from the Faculty of Civil Engineering, Monika Drzewiecka, Roman Kluger and Agata Wilk from the Faculty of Applied Mathematics, Szymon Jarzombek and Mateusz Skorupiński from the Faculty of Electrical Engineering (Mechatronics). The one of the problem that had to be solved is to implement the project in the way which will fulfil learning effects required by curricula of each faculty.

\section{2 | GOALS}

\section{1 | Hard goals}

The main hard goals of the project were:

Implement a procedure of dynamical analysis of discretized bar structures in Mathematica system. Compare the results of the above procedure with the ones obtained from student versions of professional programs for structural designing based on Finite Element Method. Design and construction of a model of 3D frame with application of 3D printing and design tools for that technology. Building an electronic system of vibration generation, control and measurement. Analysis of vibrations and comparison measurements with theoretical models. Attempts of implementing of the passive and active methods of vibration damping. This was the final aim of the project and therefore we called the project Vibration Busters. The presented paper was the first of many and focused on the description of the entire project implementation. The research results presented in the article represent only a sample works. Therefore, this paper does not present all the works, such as the results of the comparative analysis of model and practical tests, and focuses only on the results of vibration damping with the active method. The extension and presentation of more research results is planned in the next works.

\section{2 | Soft goals}

The main soft goals were:

Work in an interdisciplinary project team and implementation of general rules of project management. Training in designing elements in 3D virtual space and implementation of it in 3D printers. Training and perfecting skills in application Mathematica system, Finite Element Method system, programs for 3D printing and signal analysis.

\section{3 | IMPLEMENTATION}

The research plan with the division into tasks is presented in the form of a Gantt chart, Figure 1. There are four main stages with milestones. After one organizational week, the students trained and studied literature. The next period covered a cycle of correlated studies. As part of the project, at this stage, students prepared models of the components of the structure. Then they printed them in 3D. After the prints were made, they assembled the structure according to the indicated design assumptions. Then tests were performed. Students also built mathematical models describing the studied phenomena and allowing for active control of vibration damping. These models were implemented in the Mathematica system environment. The last two weeks are the results development and the final seminar. The cited positions [7-13] relate to projects covering single fields of study. Our project was interdisciplinary and integrated three different apparent fields: civil engineering, mathematics and mechatronics. 


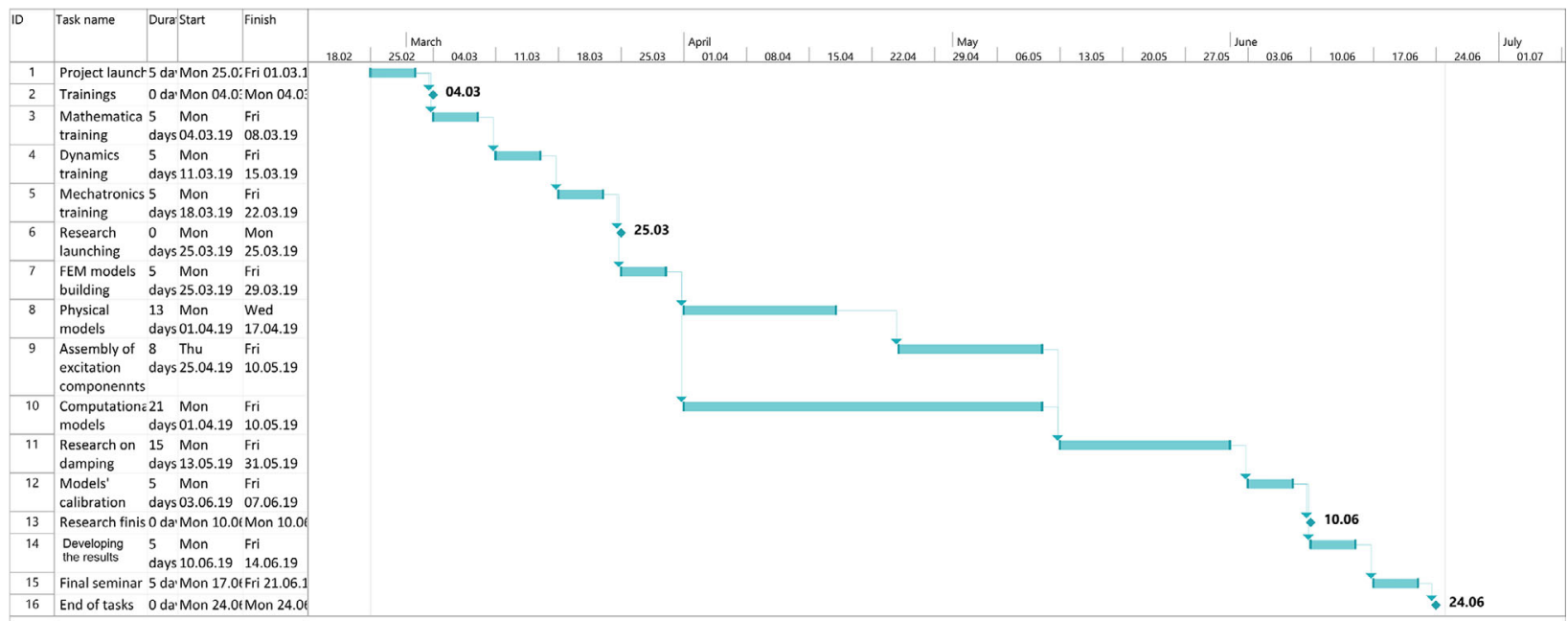

F I G URE 1 Gantt chart

The statical scheme in the form of a three-dimensional multi-storey frame was chosen because it allowed the students to conduct various experiments in the field of tuning the structure and active and passive vibration damping. Consisting of repetitive elements, it allowed for easy modification and expansion of the structure.

Due to size limitation of the paper we will only show selected extracts of the final report [14]. The implementation can be divided to three parts: mathematical, structural and mechatronic.

\section{1 | Mathematical part}

The equation of natural vibration motion is in the form (Równanie ruch drgań własnych jest postaci) [17]:

$$
\mathbf{B} \ddot{\mathbf{q}}+\mathbf{K} \mathbf{q}=\mathbf{0},
$$

where $\mathbf{B}$ is the inertia matrix, $\mathbf{K}$ is the stiffness matrix, and $\mathbf{0}$ is the zero vector. This equation is complemented by appropriate initial conditions. Solutions are sought in the form of a harmonic function

$$
\mathbf{q}(t)=\widehat{q} \sin (\omega t+\varphi),
$$

where $\omega$ is an angular frequency, $\varphi$ is the initial phase and $\widehat{q}$ is a vector of natural vibration amplitudes (wektorem amplitud drgań własnych). After substitution to the previous equation we will get

$$
\left(\mathbf{K}-\omega^{2} \mathbf{B}\right) \hat{q} \sin (\omega t+\varphi)=\mathbf{0} .
$$

Hence, we get the following homogeneous linear system

$$
\left(\mathbf{K}-\omega^{2} \mathbf{B}\right) \hat{q}=\mathbf{0} .
$$

This system will have non-zero solutions when

$$
\operatorname{det}\left(\mathbf{K}-\omega^{2} \mathbf{B}\right)=\mathbf{0} .
$$

The roots $\omega_{i}$ of the above characteristic equation are angular frequencies of free vibrations. Each eigenfrequency $\omega_{i}$ has a non-zero solution $\mathbf{w}_{i}$ called the eigenvector of free vibrations

$$
\left(\mathbf{K}-\omega_{i}^{2} \mathbf{B}\right) \mathbf{w}_{i}=\mathbf{0} .
$$


Defining a inverse matrix of the stiffness matrix $\mathbf{D}=\mathbf{K}^{-1}$ we will get the characteristic equation in the form

$$
\operatorname{det}\left(\mathbf{D} \mathbf{B}-\omega^{-2} \mathbf{I}\right)=\mathbf{0}
$$

where $\mathbf{I}$ is a identity matrix.

Students of Faculty of Applied Mathematics were responsible for implementing procedures within Mathematica [18] system. For this purpose they used the last of the above equations. Here are some extracts from their work.

The numerical model of the investigated construction was created. On the basis of this model the inertia matrix macB and the stiffness matrix mack were determined and imported into Mathematica package:

$\operatorname{In}[1]:=\operatorname{macB}=\{\{5.268,0,0\},\{0,5.413,0\},\{0,0,5.413\}\}$

$\operatorname{In}[2]:=\operatorname{macK}=-1000\{\{-13.471,17.149,-4.096\},\{17.149,-35.838,22.994\}$, $\{-4.096,22.994,-39.335\}\}$;

The inverse matrix of the stiffness matrix:

In $[3]:=\operatorname{macD}=$ Inverse $[\mathrm{macK}]$

Out $[3]=\{\{0.00030082,0.000198178,0.0000845238\},\{0.000198178,0.000175208,0.0000817846\}$, $\{0.0000845238,0.0000817846,0.0000644298\}\}$

The auxiliary matrix macA:

$\operatorname{In}[4]:=\operatorname{mac} A=\operatorname{macD} \cdot \operatorname{macB}$

Out $[4]=\{\{0.00158472,0.00107274,0.000457527\},\{0.001044,0.000948401,0.0004427\}$, $\{0.000445271,0.0004427,0.000348759\}\}$

The eigenvalues of matrix macA, that is the inverses of eigenvalues of the eigenproblem:

$\operatorname{In}[5]:=$ wart0dw $=$ Eigenvalues $[\mathrm{macA}]$

Out $[5]=\{0.00255009,0.000248666,0.0000831184\}$

The eigenvalues of the eigenproblem:

$\operatorname{In}[6]:=$ wartWla $=1 /$ wart0dw

Out $[6]=\{392.142,4021.45,12031$.

The vector of frequencies:

$\operatorname{In}[7]:=\backslash[$ Omega] $0=\operatorname{Sqrt}[$ wartWla $] /(2 \mathrm{Pi})$

Out $[7]=\{3.15168,10.0928,17.4571\}$

The periods of vibrations for the respective frequencies:

$\operatorname{In}[8]:=\quad \mathrm{T}=(2 \backslash[\mathrm{Pi}]) \wedge[\mathrm{Omega}] 0$

Out $[8]=\{1.9936,0.622541,0.359922\}$

The eigenvectors of matrix macA, and simultaneously the eigenvectors of the considered eigenproblem:

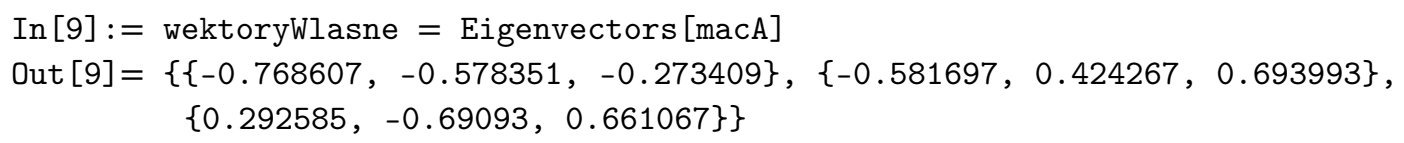

Eigenmatrix:

$\operatorname{In}[10]:=$ macW $=$ Transpose [wektoryWlasne]

Out $[10]=\{\{-0.768607,-0.581697,0.292585\},\{-0.578351,0.424267,-0.6909\} 3$, $\{-0.273409,0.693993,0.661067\}\}$ 


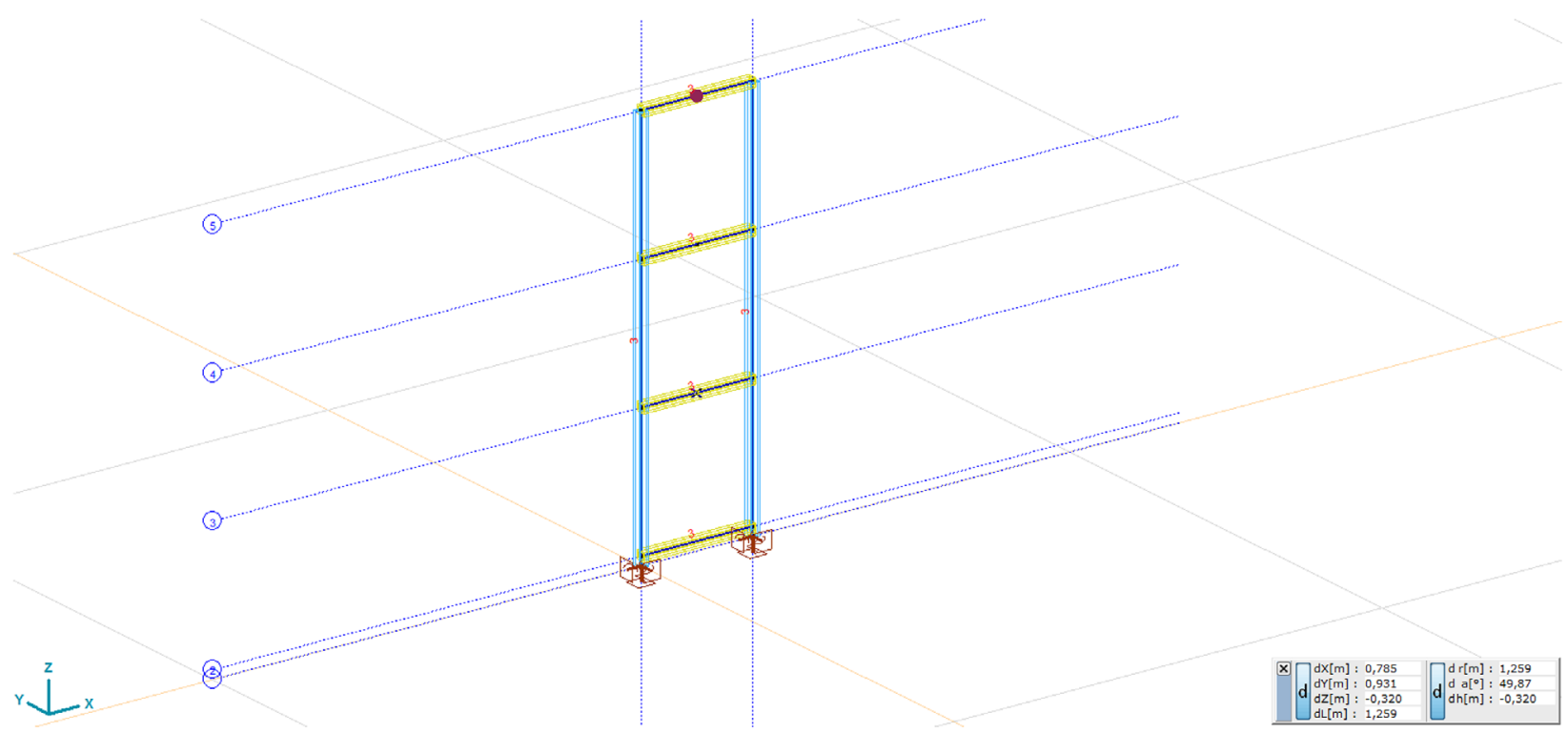

F I G U RE 2 Structural analysis of 2D model

For the known frequencies of the system the procedure for finding the eigenvectors can have the form:

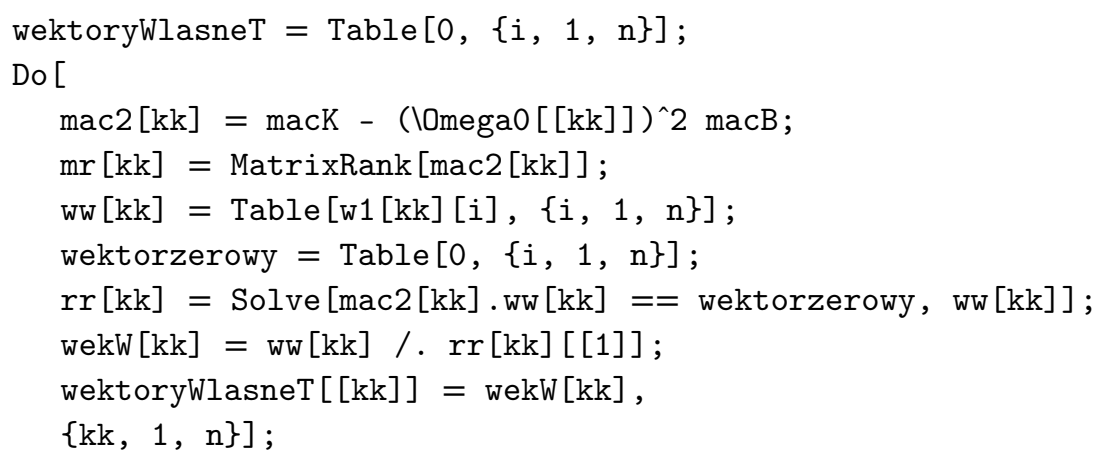

The above procedure computes eigenvectors for the matrix:

$$
\mathbf{M}=\mathbf{K}-\omega^{2} \mathbf{B},
$$

where $\mathbf{K}$ is a stiffness matrix, $\mathbf{B}$ is an inertia matrix and $\omega$ is an angular frequency.

\section{2 | Structural part}

Within this part 2D and 3D models were analysed within a Finite Element Method program (Figures 2 and 3) and results were first used to verify mathematical procedures. It was done by students of Civil Engineering and Mathematics.

The pre-calculations were used to design a frame and to plan an experimental part. In the next stage all students learned to design elements for 3D frame. 3D printing is a modern technology of incremental production that allows you to recreate a virtual 3D model in reality. Depending on the type of printer, this technology allows you to create objects, including plastic, metal or concrete. The printer used in the project allows you to create objects from plastic using the FDM (Fused Deposition Modelling) method. This method involves applying molten material layer by layer using a head moving in three axes of the coordinate system $(x, y, z)$.

A three-segment frame was adopted as a demonstrator and an example structure in the project. The adopted structure makes it possible to assemble the whole structure from connectors (corners) and arms which form a frame. This was the most time consuming part of the project mainly because troubleshooting with 3D printing connected with high accu- 


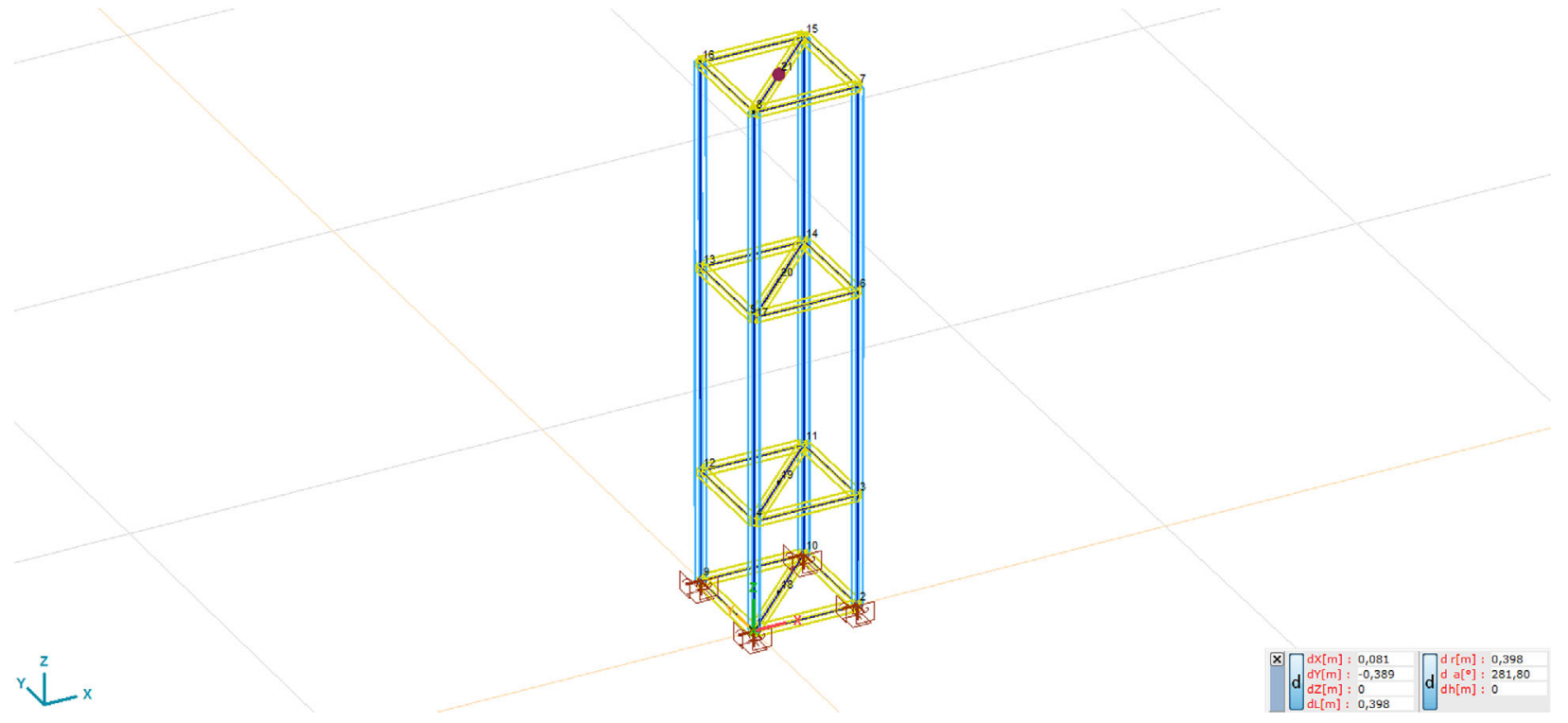

F I G U RE 3 Structural analysis of 3D model

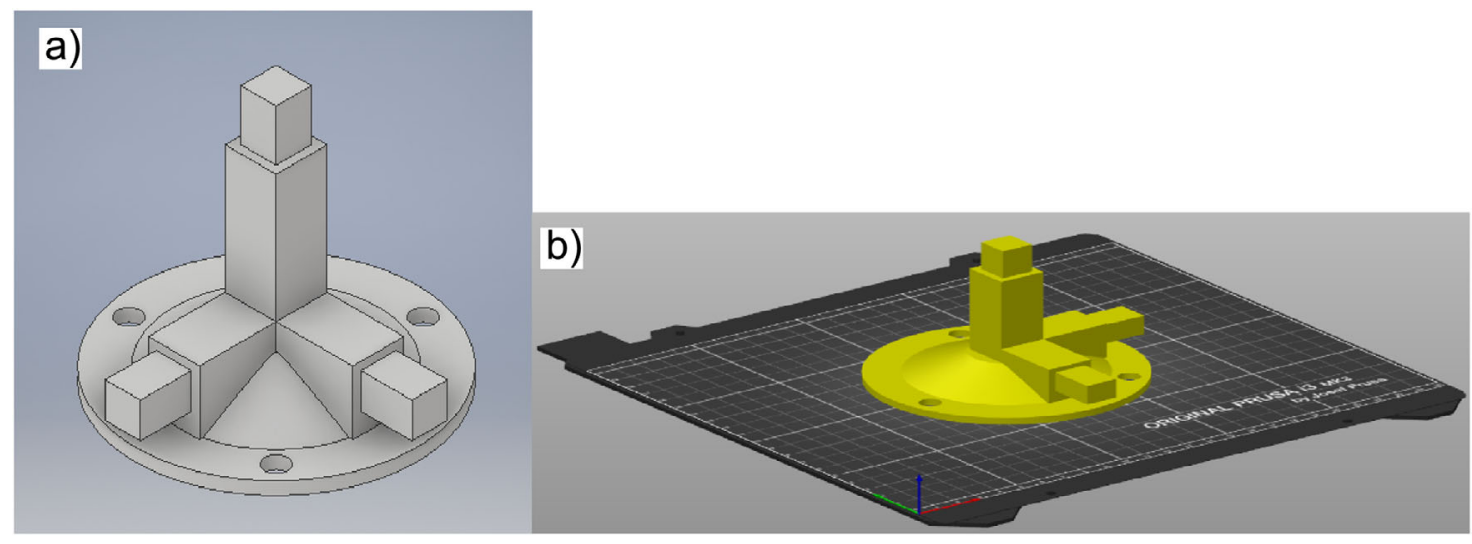

F I G U R E 4 Model of the frame support element in Autodesk Inventor ( $a$ ) and model in the 3D printing program (b)

racy and strength of the structure. All work was divided for parts. In the first step elements were designed in Autodesk Inventor, Figure 4 a). Next the model was imported to the 3D printing software for generating *.gcode file for controlling of work of 3D printer, Figure $4 \mathrm{~b}$ ) and at the end elements were printed. The printed out elements are shown in Figure 5.

Autodesk Inventor was used to calculate dynamic characteristic of the structure (modal frequency analysis) as a 3D model. Results were compared with discrete models developed in the previous stage. Figure 6 shows the deformation of model for exemplary simulation calculated in FEM toolbox of Autodesk Inventor.

\section{3 | Mechatronic part}

The research stand is presented in Figure 7. It was mounted in the laboratory of the Department of Mechatronics at the Faculty of Electrical Engineering. The frame is loaded with four electrical DC motors generating vibrations with varied frequencies. In the configuration presented here two motors were placed on the upper level in vertical position and two a level below in horizontal position. Students did experiments in different configurations.

One of the phenomena observed during the experiment was rumble of vibrations of the structure if frequency of excitation is close to one of the natural frequencies of the structure. The characteristic course of the phenomenon is shown in Figure 8. The displacement shown here were measured with a precise laser displacement detectors. 


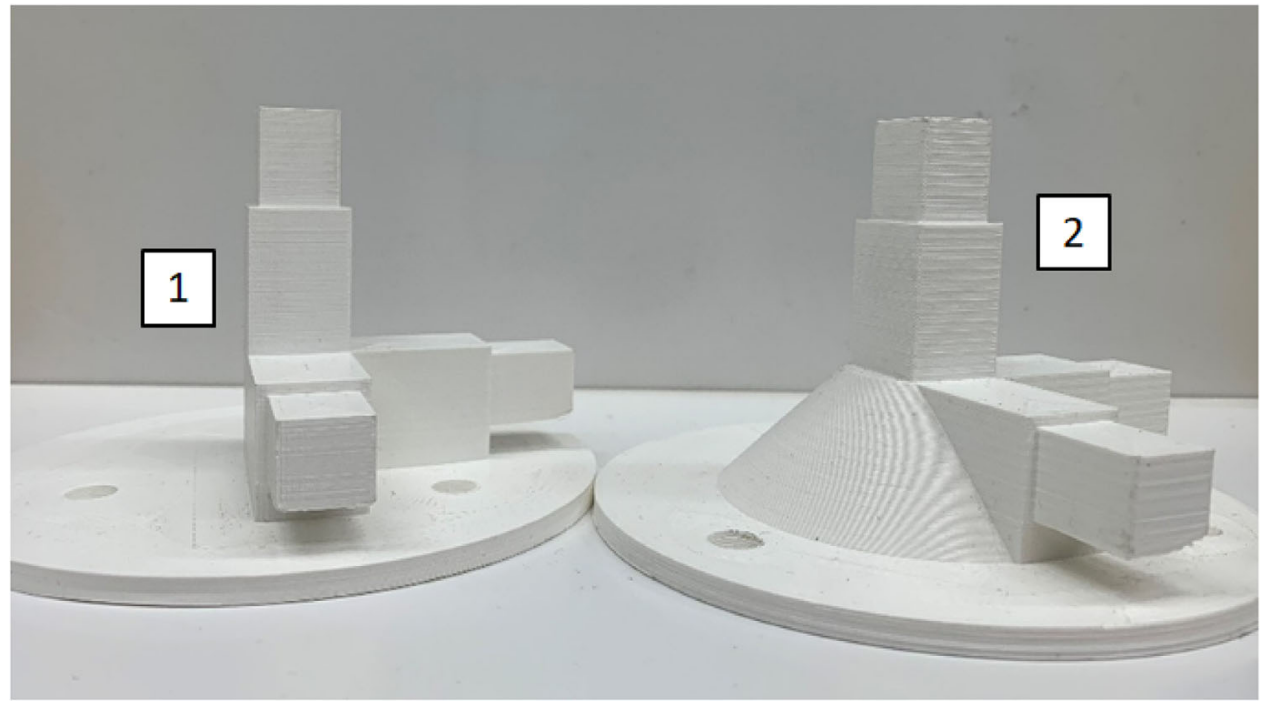

F I G U R E 5 Printed out elements: in higher resolution of printing (1) and in lower resolution of printing (2)

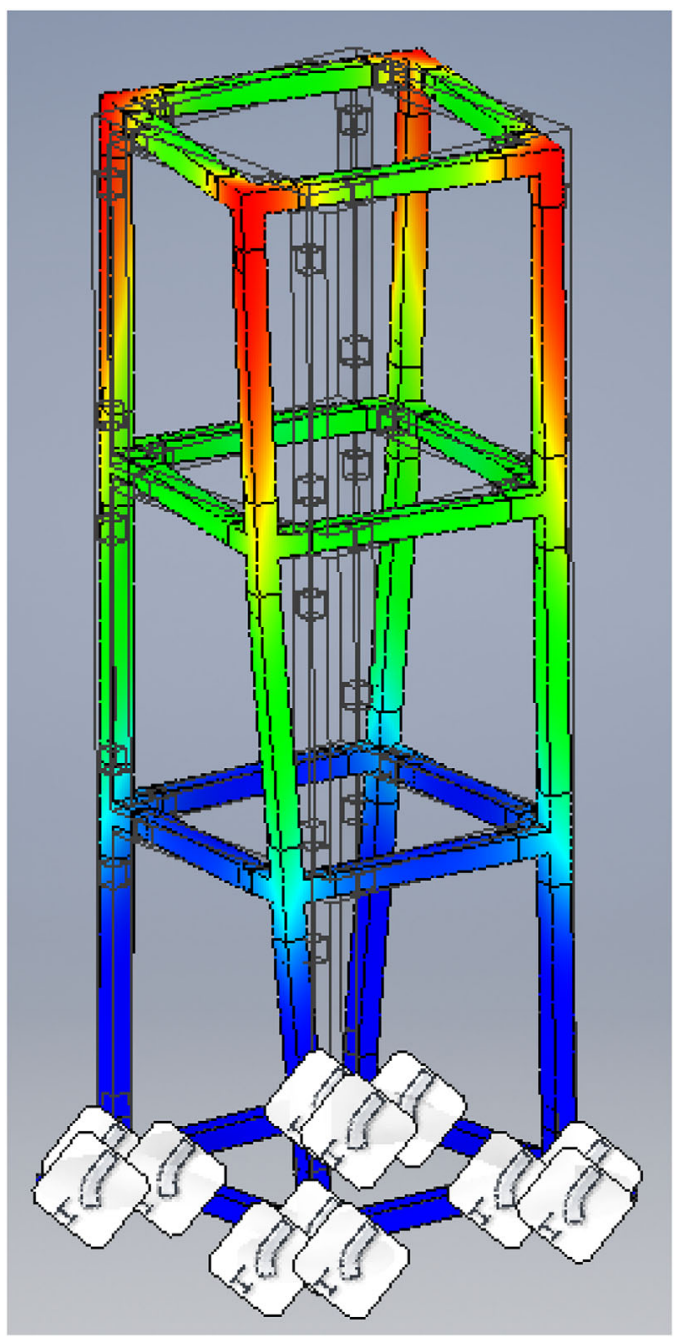

F I G U R E 6 Modal analysis of the frame 


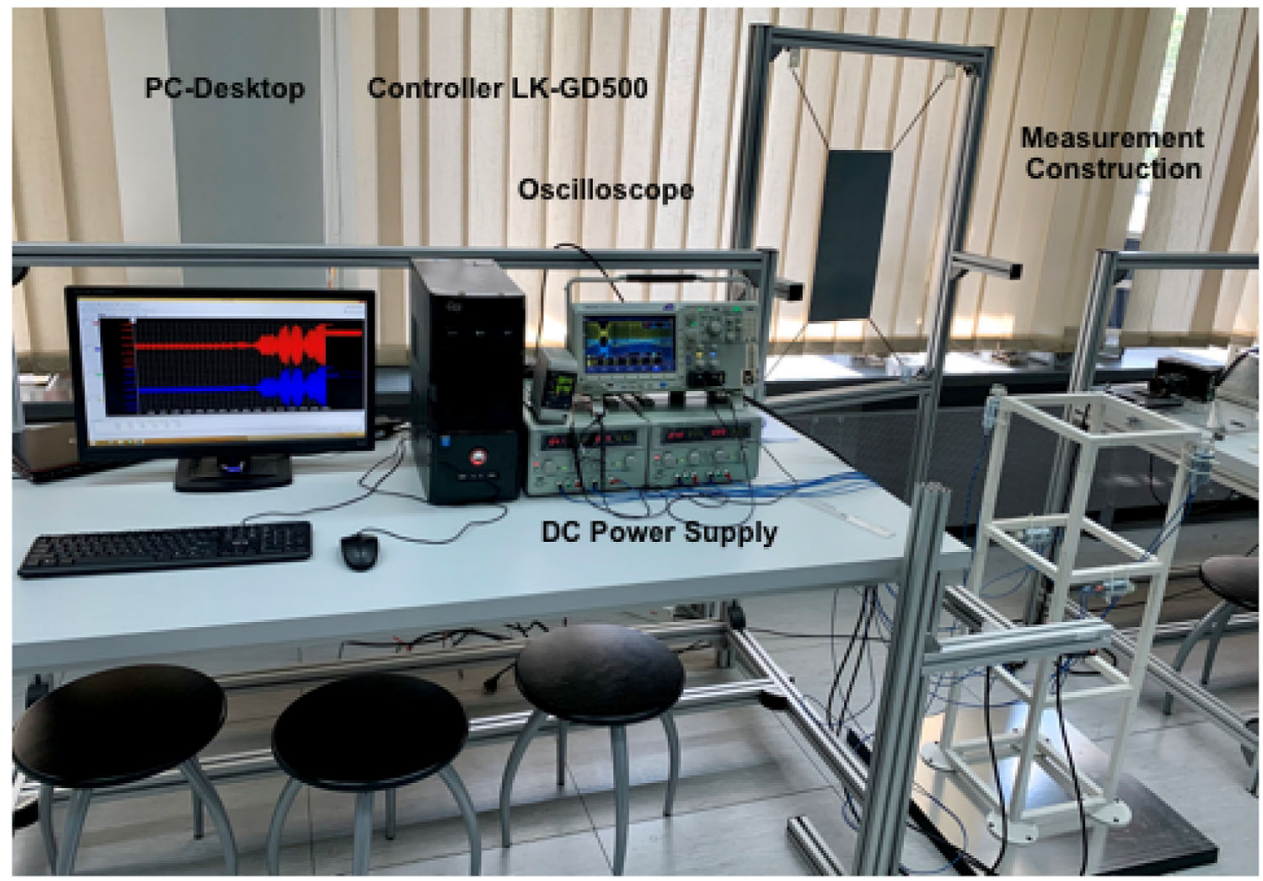

F I G U R E 7 Research installation

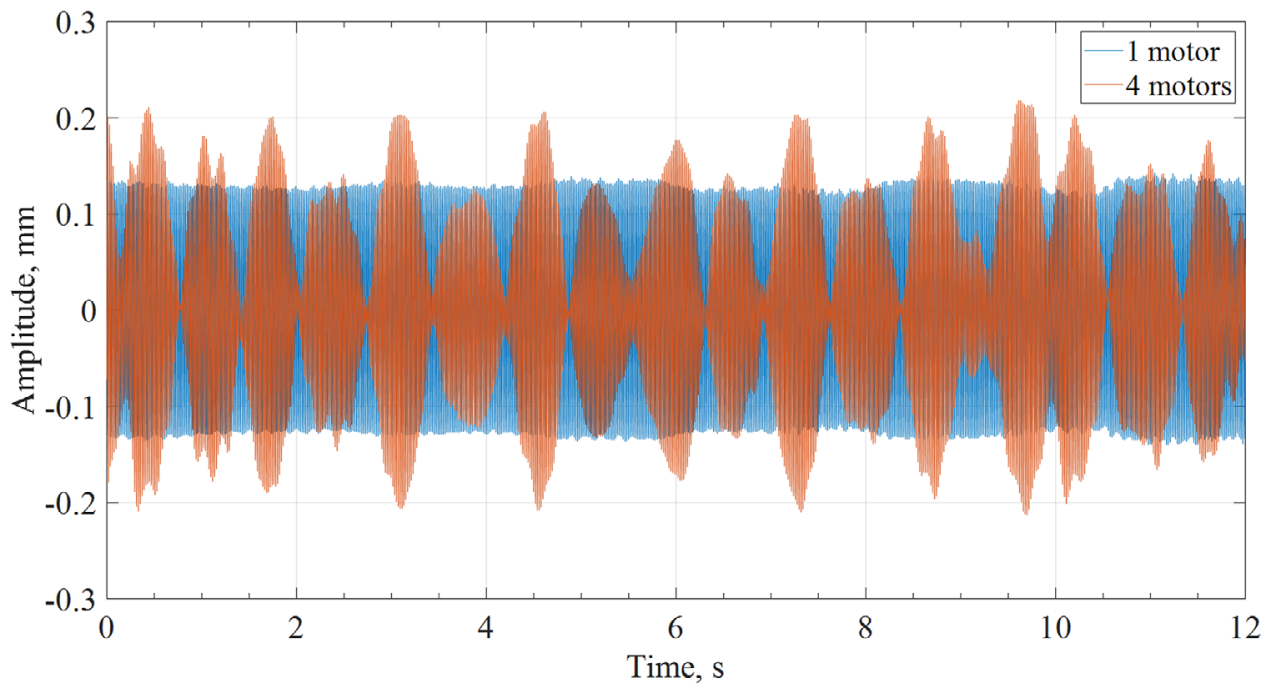

F I G U R E 8 Sample analysis of vibrations for one motor operating (blue curve) and four motor operating (red curve)

Figures 9 and 10 show results of the frequency analysis for vibrations presented in figure 8. In the experiment one and four motors were used. Comparing the vibration amplitudes in Figures 9 and 10, it can be seen that after switching on all four motors, the vibration generated by one motor was suppressed.

The damping effect is related to the vibrations forced by the motors mounted on the structure. When the vibrations are excited with one motor for a given frequency, vibrations of a specific structure are generated. When all four motors are turned on, the frequency of vibrations generated by the inductors is not the same, therefore periodic changes in the amplitude of the resulting vibrations resulting from the composition of vibrations of similar frequencies are observed. In fact, the rumbling effect causes the vibration amplitude for the examined structure to be damped in a special case. Due to time limitation on this phenomenon was checked and researched with this installation. Research for other structure will be continued in the future. 


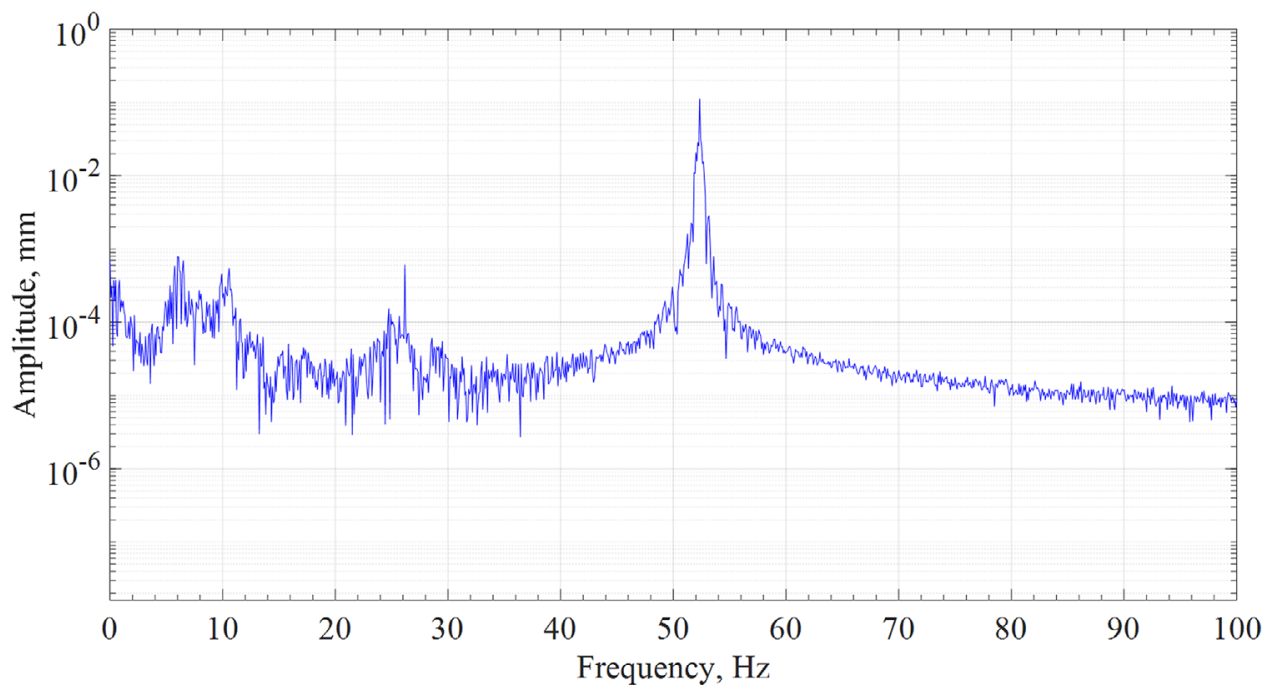

F I G U R E 9 Result of frequency analysis of vibrations for one motor operating

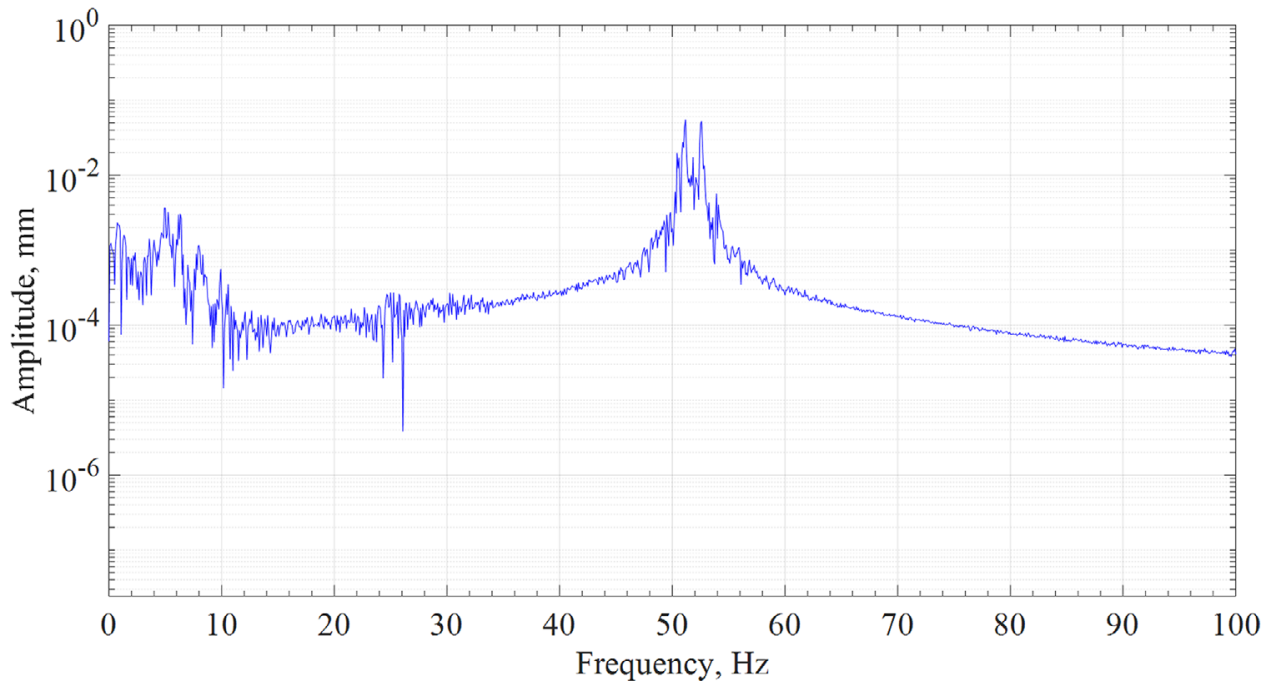

F I G U R E 10 Result of frequency analysis of vibrations for four motor operating

\section{4 | SHARED EXPERIENCE}

During the implementation of the project, students had the opportunity to broadly exchange experiences and knowledge acquired during their studies. During lectures, seminars and laboratory work, they had the opportunity to acquire knowledge gained in other fields of study as well as to acquire practical skills in the use of programs and devices. The timely implementation of tasks is presented in Figure 1.

The joint work of students was organized in the form of seminars and laboratory classes. Initially 8 hours a week. Later, in the course of the laboratory tests, this number increased significantly, resulting from the requirements of the tests performed. During the joint classes, students learned about selected issues in the field of mathematical modelling, building 2D and 3D models in AxisVM, the use of 3D printing to build a physical model, as well as the basics of mechatronics. Students also got acquainted with specialized software such as: Mathematica package, AxisVM, Autodesk Inventor.

During the project, students also participated in lectures and laboratory classes conducted by the invited expert. As part of these classes, students learned about the construction and classification of electromechanical converters and methods of their control. They used the knowledge gained from these classes to develop a construction of the vibrating system used to excite vibrations created in the design of a truss made by 3D printing. 
During the work, the students exchanged their knowledge and experience with their colleagues from other specializations. Students did all the work together. At the same time, the main contractors of works related to mathematical modelling former students of Mathematics. Moreover, the other students helped them, increasing their knowledge in this area. It was similar with the works on the design and construction of the physical model and conducting an experiment on a physical model. In this case, respectively, the main participants were students of Civil Engineering and Mechatronics.

All of us gained new knowledge, skills and competencies. Mathematicians found, first of all, that their vast knowledge has important practical application. Civil engineers, whose education is based mostly on designing, had opportunity to work in the laboratory of mechatronics. Mechatronics had of all possibility to extend their knowledge to the bigger scale.

\section{5 | CONCLUSIONS}

Modern Industry 4.0 technologies often require the use of highly efficient air-conditioning systems or the use of vibrating machines with simultaneous high vibration reduction regimes. Especially in existing buildings that are being adapted to new production, the only possible location for fans that generate vibrations is the roof of the building. This solution often causes problems that prevent the proper functioning of the facility. The fight with this type of phenomena requires the cooperation of specialists from several fields and the ability to model these issues mathematically. The combination of students of three faculties in the project: construction, mathematics and mechatronics allowed for the education of a group of graduates specialized in vibration damping and reduction methods and mathematical modelling of this type of issues.

Despite problems encountered within implementation of the project we can say that crucial results fulfiled expected goals. The hard results of the project, especially the newly developed installation will be used in further research and education. We plan to continue the project within Master Degree course next year. The most important are unique soft skills achieved both by students and supervisors. The extraordinary experience will bear fruits for all of us, our University and future employers of our students. They gained ability of working in interdisciplinary teams and built knowledge and skills in solving difficult problems of dynamics. It is worth to mention that all of this was done on the early stage of their studies. They were students of the bachelor course. For supervisors it was also a possibility to learn about for future cooperation among faculties within other projects.

\section{ACKNOWLEDGMENTS}

The project has been developed within implementation project "Silesian University of Technology as a center of modern education based on research and innovations" (POWR.03.05.00-IP.08-00-PZ1/17) [15], financed by the European Funds of the Operational Program Knowledge Education Development. Among other activities there is a project called "Individual Study Programs implemented in the form of Project Based Learning” [16]. It was the second edition of it.

\section{REFEREN CES}

[1] Project-Based Learning, Edutopia \& George Lucas Educational Foundation (2016). https://www.edutopia.org/project-based-learning

[2] What is Project Based Learning, Defined Learning (2019). https://www.definedstem.com/blog/what-is-project-based-learning/

[3] Dewey, J.: My pedagogic creed. School J. LIV(3), 77-80 (1897)

[4] Dewey, J.: Education and Experience. Touchstone, New York (1938/1997)

[5] Blumenfeld, P.C., Soloway, E., Marx, R.W., Krajcik, J.S., Guzdial, M., Palincsar, A.: Motivating project-based learning: sustaining the doing, supporting the learning. Educ. Psychologist 26(3-4), 369-398 (1991)

[6] Bender, W.N.: Project-Based Learning: Differentiating Instruction for the 21st Century, 1st ed. Corwin Press, Thousand Oaks, CA (2012)

[7] Gavin, K.: Case study of a project-based learning course in civil engineering design. Eur. J. Eng. Educ. 36(6), 547-558 (2011)

[8] López-Querol, S., Sánchez-Cambronero, S., Rivas, A., Garmendia, M.: Improving civil engineering education: Transportation geotechnics taught through project-based learning methodologies. J. Professional Issues Eng. Educ. Pract. 141(1), 04014007 (2015)

[9] Miranda, M., Saiz-Linares, Á., da Costa, A., Castro, J.: Active, experiential and reflective training in civil engineering: Evaluation of a project-based learning proposal. Eur. J. Eng. Educ. 1-20 (2020)

[10] Doppelt, Y.: Assessment of project-based learning in a MECHATRONICS context. J. Technol. Educ. 16(2), 7-24 (2005)

[11] Wang, Y., Yu, Y., Wiedmann, H., Xie, N., Xie, C., Jiang, W., Feng, X.: Project based learning in mechatronics education in close collaboration with industrial: Methodologies, examples and experiences. Mechatronics 22(6), 862-869 (2012)

[12] Capraro, R.M., Capraro, M.M., Morgan, J.R.: STEM Project-based Learning: An Integrated Science, Technology, Engineering, and Mathematics (STEM) Approach. Springer Science \& Business Media (2013)

[13] Holmes, V.-L., Hwang, Y.: Exploring the effects of project-based learning in secondary mathematics education. J. Educa. Res. 109(5), 449463 (2016) 
[14] Walentyński, R., et al.: Vibration busters. Final report of the PBL project (in Polish), Silesian University of Technology, Gliwice (2019)

[15] Silesian University of Technology as a center of modern education based on research and innovations (2018). http://www.cik40.polsl.pl/ (in Polish)

[16] University News: Student recruitment at Project Based Learning (2018). https://www.polsl.pl/Lists/AktualnosciUczelniane/DispForm. aspx?ID=2479 (in Polish)

[17] Chmielewski, T., Zembaty, Z.: Basics of Building Dynamics (in Polish). Arkady, Warsaw (1998)

[18] Wolfram, S.: An Elementary Introduction to the Wolfram Language. Wolfram Media, Champaign (2017).

How to cite this article: Walentyński, R, Słota D, Szczygieł M. Vibration busters: An interdisciplinary approach to learning of dynamical systems. Z Angew Math Mech. 2021;e202000110. https://doi.org/10.1002/zamm.202000110 